STUDI

FRANCESI

\section{Studi Francesi}

Rivista quadrimestrale fondata da Franco Simone

186 (LXII | III) | 2018

Varia

\title{
GÉRARD GASARIAN, La poésie et son double. Apollinaire, Desnos, Ponge, Char et Bonnefoy
}

\section{Fabio Scotto}

\section{(2) OpenEdition}

\section{Journals}

\section{Edizione digitale}

URL: http://journals.openedition.org/studifrancesi/15839

DOI: 10.4000/studifrancesi.15839

ISSN: 2427-5856

\section{Editore}

Rosenberg \& Sellier

\section{Edizione cartacea}

Data di pubblicazione: 1 décembre 2018

Paginazione: 531-532

ISSN: 0039-2944

\section{Notizia bibliografica digitale}

Fabio Scotto, "Gérard gasarian, La poésie et son double. Apollinaire, Desnos, Ponge, Char et Bonnefoy», Studi Francesi [Online], 186 (LXII | III) | 2018, online dal 01 janvier 2019, consultato il 06 janvier 2021. URL: http://journals.openedition.org/studifrancesi/15839; DOI: https://doi.org/10.4000/studifrancesi. 15839

Questo documento è stato generato automaticamente il 6 janvier 2021.

\section{(c) $($ ) $(9)$}

Studi Francesi è distribuita con Licenza Creative Commons Attribuzione - Non commerciale - Non opere derivate 4.0 Internazionale. 


\title{
GÉRARD GASARIAN, La poésie et son double. Apollinaire, Desnos, Ponge, Char et Bonnefoy
}

\author{
Fabio Scotto
}

\section{NOTIZIA}

GÉRARD GASARIAn, La poésie et son double. Apollinaire, Desnos, Ponge, Char et Bonnefoy, Paris, Hermann, 2016, «Savoir lettres», 310 pp.

1 Professore all'Università di Tufts nel Massachusetts, Gérard GASARIAN è autore di studi sulla poetica e di alcune apprezzate monografie su Bonnefoy, Baudelaire e Breton. Questo suo volume, il cui titolo parafrasa dichiaratamente il noto saggio di Artaud del 1938, intende affrontare in cinque figure maggiori della poesia francese contemporanea il fatto che comunque, senza voler «transposer à la poésie, telles quelles, les idées d'Artaud sur le théâtre [...] la conscience poétique, toujours active, s'appréhende et se réfléchit à travers des doubles d'elle-même» («Avant-propos», p. 7).

Attraverso cinque studi, rispettivamente dedicati ad Apollinaire, Desnos, Ponge, Char, Bonnefoy, il critico intende quindi esplorare le dinamiche poetiche messe in atto da un'opera esemplare di ciascuno di essi; ciò può forse in apparenza prestare il fianco al rischio di parzialità dell'analisi, se confrontata all'ampiezza del corpus globale delle rispettive produzioni, in realtà l'argomentazione ne guadagna in capacità d'analisi e d'approfondimento, per via della riduzione del campo d'osservazione, anche riducendo la tentazione digressiva, spesso dispersiva.

3 «Apollinaire: le bruit des souvenirs (Poésie et Autobiographie)» (pp. 13-80) si sofferma prevalentemente sulla raccolta Alcools (1913) e sulla problematica dell'auto-confessione che sovrappone al mal d'amore il mal di scrivere in una continua interconnessione che sdoppia il soggetto lirico neutralizzando il suo intento liberatorio che gli viene specularmente ributtato addosso nell'atto stesso che tenterebbe di confessarsi, così 
trasformando il dire nell'angoscia dell'espressione. Si vedano, a tal riguardo, ad esempio, ne Le Musicien de Saint-Merry, nel verso «Jouant l'air que je chante et que j'ai inventé», la modalità auto-riflettente della poesia di Apollinaire, il quale, ritrovandosi nella propria creatura, «[...] en profite pour se voir en train de créer, se contemplant au travail dans le jeu d'un autre» (p. 71). Ne deriva quindi il suo duplice attaccamento al canto e all'oggetto del canto (p. 79).

Mentre in «Desnos: le chant de la sirène (Poésie et Onirisme)» (pp. 81-132) è esplorata, muovendo da Corps et biens (1930), la dimensione onirico-erotica (è noto infatti come Desnos nelle sedute ipnotiche surrealiste fosse particolarmente portato al trance), qui vista come una sorta di naufragio cui il poeta s'abbandona in un continuo moto di perdita e ritrovamento di sé. Tramite l'inversione di senso, spesso operata su espressioni della lingua comune («Tout rien», in luogo di «Tout ou rien», p. 83, o il celebre Minuit à Quatorze heures, p. 86), Desnos mette in atto un meccanismo di moltiplicazione dei nessi logici e retorici che opera sdoppiamenti di sapore tragicomico, il primo dei quali è quello di invertire i rapporti fra notte e giorno quanto al desiderio se «Contrevenant au modèle freudien, Desnos n'attend pas la nuit pour y satisfaire, inconsciemment, ses désirs de la journée. Tout au contraire, il attend le jour pour y satisfaire, éveillé, ses rêves de la nuit» (p. 87).

5 Con «Ponge: la parabole du pré (Poésie et Cosmologie)»(pp. 133-180), Gasarian, ovviamente riguardo alla Fabrique du pré (1971), studia come, in effetti, ogni produzione poetica vada di pari passo con una parallela riflessione sul processo stesso di sua creazione. Da questo punto di vista, la creazione del prato metaforizza la genealogica creazione stessa di quello che Blanchot chiama l'espace littéraire, dato che «Avec ce pré dont l'émergence est contemporaine du texte, on assiste à l'inauguration d'un nouvel espace, où s'informe un nouvel ordre moral et culturel» (p.147). L'elemento genealogico caratterizza anche il ricco capitolo «Char: la voix des fontaines (Poésie et Généalogie)»(pp.181-241), che in Fureur et mystère (1948) è tutto teso al recupero rabdomantico delle fonti dell'infanzia per farne uno slancio verso il futuro che leghi spazio e tempo in un'unica linea ideale tale da fare della poesia l'oggetto stesso dell'amore del poeta (p. 240).

6 Infine, in «Bonnefoy: les mots de la terre (Poésie et Archéologie)» (pp. 243-278), lo studioso mostra come, ne L'Arrière-Pays (1972), da più parti ritenuto uno dei testi di prosa maggiori del secolo scorso, il poeta ancori la sua scrittura ad alcune letture che lo riportano a una coscienza arcaica del mondo e della terra, prossima al mito (aspetto riguardo al quale tuttavia l'atteggiamento di Bonnefoy permane enigmatico e critico), inteso come racconto di un'avventura di lettura che si fa scrittura della stessa: «Déchiffrer les images, leur trouver un équivalent verbal où elles s'élucident en une légende plus claire que les signes obscurs dont elles procèdent, telle est la tâche que se propose Bonnefoy» (p. 255).

7 La «Conclusion (Poésie et Philologie)» (pp. 279-307), nell'allargare il discorso ad altre figure e poetiche, individua nell'intermittenza del soggetto lirico e nell'interminabilità del meccanismo di apparizione e scomparsa il tratto dominante di quella che Baudelaire ebbe a definire la "rhétorique profonde» della poesia, a ben vedere, nella dialettica del "je" et del "tu", l'uno dei suoi doppi possibili che questo ricco, stimolante e ben documentato saggio contribuisce a rivivificare. 